\title{
An Excitation Circuit of the Cell in Optically Pumped Magnetometer
}

\author{
Chao Wang, Zhijian Zhou, and Defu Cheng
}

\begin{abstract}
Cell is the key component in an optically pumped magnetometer. It is necessary to light the cell before measurement and to maintain the illuminated state. The accuracy and stability of magnetic values from the instrument are closely related to the brightness and stability of the cell. The cell is also the largest power dissipation component in the sensor probe, so the overall energy consumption of the magnetometer is highly correlated with it. This paper studies the excitation circuit of cell in the magnetometer. Firstly, we demonstrate the resistivity characteristic of a cell using simulations. After that, based on the combination of signal source impedance and transmission line impedance, the matching network of excitation circuit is analyzed. We demonstrate that both T-network and $\Pi$-network can achieve the impedance matching of the transmitter circuit by a simulation experiment, under the condition of $50 \mathrm{MHz}$ signal, $10 \Omega$ source impedance, and $50 \Omega$ transmission line impedance. T-network shows the best performance in frequency selectivity and energy transfer. Finally, the simulation experiment also proves that a circuit composed of a self-coupled coil and an LC parallel resonant network can realize the impedance matching and the passband selection of the receiver circuit by optimizing values of the inductance and capacitance, and turns of the self-coupled coil simultaneously. The power consumption of the whole high-frequency excitation circuit of cell in the optically pumped magnetometer is only about $6 \mathrm{~W}$.
\end{abstract}

Keywords-Optically pumped Magnetometer, cell, excitation circuit, impedance matching.

\section{INTRODUCTION}

$\mathrm{O}$ ptically pumped magnetometer is a type of magnetic survey instrument using the principle of atomic magneto-optical resonance principle[1-4]. In the field of magnetic detection, the magnetometer is one of the most highly accurate and most watched instruments. It is widely used in geological exploration, satellite magnetic survey, and medical testing[5-7]. In recent years, satellites in the European space agency's SWRAM space exploration program have been equipped with a helium optically pumped magnetometer with a sensitivity of $1 \mathrm{pT} / \sqrt{\mathrm{H}_{\mathrm{z}}}$ [8-11]. The magnetometer can also be used to detect biomagnetism signals, and magnetic microscopy has been achieved with the magnetometer. Researchers at Okayama University in Japan have used the optically pumped

This work was supported by the Special Projects for Monitoring, Warning and Prevention of Major Natural Disasters, the National Key Research and Development Program of China 2018 (Grant No. 2018YFC1503803 and 2018YFC1503903).

C. Wang is with the College of Instrumentation and Electrical Engineering, Jilin University, Changchun, China (e-mail: chaow15@mails.jlu.edu.cn)

Z. Zhou is with the College of Instrumentation and Electrical Engineering, Jilin University, Changchun, China (e-mail: zhouzhijian@jlu.edu.cn)

D. Cheng is with the College of Instrumentation and Electrical Engineering, Jilin University, Changchun, China (e-mail: chengdefu@jlu.edu.cn) magnetometer to measure the human brain's magnetic field and get high-quality data[12-14].

In the cell of optically pumped magnetometer, an atom in the ground state can be excited by an external signal to the metastable state energy level. An atom in a metastable state can have a Zeeman splitting in a strong magnetic field, then, the atoms form a specific optical orientation because of the optical pumping action. At the same time, the effect of the external magnetic field and the Radio Frequency (RF) magnetic field provided by an RF coil to the cell make the metastable state atoms a magnetic resonance. The intensity of transmitted light through the cell varies with the frequency of the RF field, and it is the weakest when the magnetic resonance occurs. The value of the RF signal $f_{0}$ at magnetic resonance can be measured by the change of light intensity. The magnetic field value $\mathrm{B}_{0}$ is proportional to $\mathrm{f}_{0}$, we get $\mathrm{B}_{0}[15,16]$. Therefore, the atomic magneto-optical resonance principle of magnetic measuring determines the core position of the cell[ $[15,16]$. It is necessary to light the cell before measurement and to maintain the illuminated state in the process of work.

By solving magneto-optical Bloch equations and the related experiments, we can attest that the test sensitivity of optically pumped magnetometer has a direct correlation with the optical pumping rate and the atomic relaxation rate in the atomic magneto-optical resonance principle[17-19]. William Happer, et al.[ref] demonstrated that external factors such as gas concentration, pressure, brightness, brightness stability of the cell and the brightness, brightness stability of light source. influence the optical pumping rate and the atomic relaxation rate. Recently, many teams, including Peking University and Zhejiang University in China, have conducted in-depth studies on the quality of the light source[20-22]. However, the luminescent quality of the cell is relatively neglected. In addition, the cell is also the primary power dissipation component in the sensor probe. At present, in the commonly used magnetometer, the power consumption of Cs-3 cesium optically pumped magnetometer probe is up to $60 \mathrm{~W}$ at start-up time and around 20W after stabilization. RS-HGB4A and RS-DGB4A helium optically pumped magnetometer of China shipbuilding industry 715th Research Institute have a power consumption of around $50 \mathrm{~W}$. So, in order to improve the data quality and reduce the power consumption of optically pumped magnetometer, it is necessary to design a high-frequency excitation circuit with reasonable structure and energy transfer to[23-27].

In this paper, the signal source impedance of the circuit is obtained and the impedance characteristic of the load (cell) is determined, and the overall structure of high-frequency 


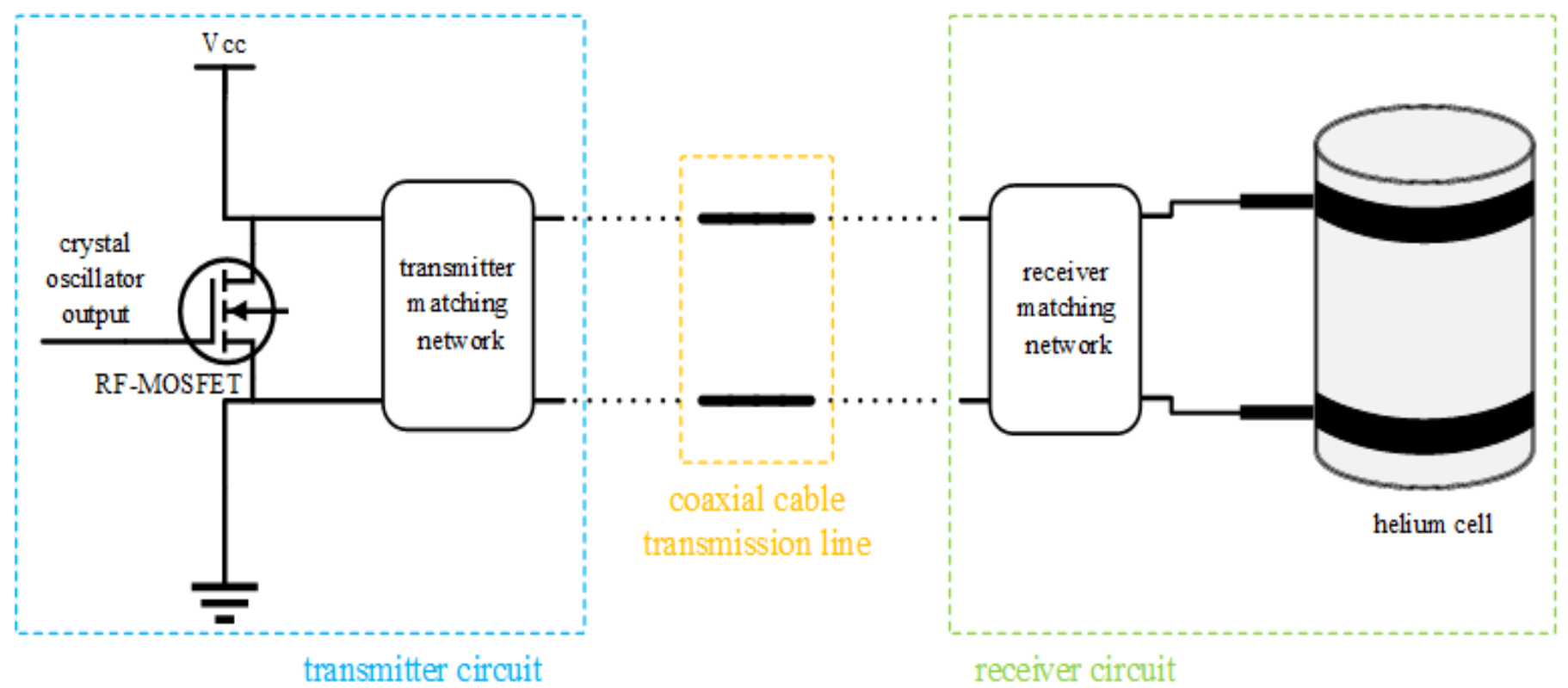

Fig. 1. Structure partition of the high-frequency excitation circuit.

excitation circuit is designed based on this. Section III presents the impedance matching and frequency resonance network design of high-frequency excitation, introduces the circuit analysis and parameter estimation methods of L-network, T-network, П-network, LC parallel resonant network, and self-coupling coil. In Section IV, the corresponding simulation experimental results of different circuit forms and parameters are given and analyzed. In conclusion, our paper guarantees the brightness of the cell in the case of minimum energy loss and the total power consumption $6 \mathrm{~W}$.

\section{DESIGN PRINCIPLE OF HIGH-FREQUENCY EXCITATION CIRCUIT}

The high-frequency excitation circuit of the optically pumped magnetometer can be divided roughly into two parts - a signal transmitter circuit and a signal receiver circuit which are separated by coaxial cable transmission line. Specifically, the signal transmitter circuit is divided into a signal source and a transmitter matching network to realize the impedance matching of the source and the transmission line. The signal source includes a crystal oscillator and a Radio Frequency (RF) power Metal Oxide Semiconductor Field Effect Transistor (MOSFET). The signal receiver circuit is divided into a load and a receiver matching network to realize the impedance matching of the transmission line and the load. The circuit structure partition is shown in Fig.1.

In order to achieve the maximum efficiency of power transmission, a passive matching network is inserted between the wave source and the load to make the load impedance and the wave source impedance match each other. Additionally, the matching network functions in part as a filter also ensures the power of the work-frequency signal is transmitted and the undesired harmonic components and interference are suppressed.

\section{A. Signal source and transmission line impedance}

The MOSFET is a voltage control device. When the output is saturated, the drain output current in and the gate-source voltage VGS are linear in a certain range. Therefore, the previous part of transmitter circuit can be used as a single output network in Fig.1. Circuit analysis based on the equivalent theorem of David south or NORTON, assuming that the internal resistance of the source is $\mathrm{r}$, and the high-frequency AC signal $\mathrm{u}_{\mathrm{s}}$ expressed as follows:

$$
\mathrm{u}_{\mathrm{s}}=\mathrm{U}_{\mathrm{sm}} \cos \omega \mathrm{t}
$$

$\mathrm{U}_{\mathrm{sm}}$ is the signal peak voltage, $\omega$ is the frequency of the signal. Assuming the MOSFET output load is $\mathrm{R}_{\mathrm{Ls}}$, according to the maximum power transfer theorem, when $R_{L s}=r$, the output power is the maximum, defined by the following:

$$
\mathrm{P}_{\mathrm{Lomax}}=\frac{\mathrm{U}_{\mathrm{sm}}^{2}}{8 \mathrm{r}}=\frac{\mathrm{U}_{\mathrm{R}_{\mathrm{L}} \mathrm{m}}^{2}}{2 \mathrm{R}_{\mathrm{Ls}}}
$$

The typical output power of chosen RF-MOSFET is $6 \mathrm{~W}$. Circuit power supply $\mathrm{V}_{\mathrm{cc}}=12 \mathrm{~V}$, MOSFET saturation tube pressure drop $\mathrm{V}_{\mathrm{dss}} \approx 1 \mathrm{~V}$, according to (2), when the maximum output power is obtained $R_{L s}=r=10 \Omega$. The impedance of the coaxial transmission line is $50 \Omega$.

\section{B. Cell impedance}

The cell is a cylindrical sealed glass container filled with gas. When the frequency of alternating electric field in the cell is greater than the movement rate of charged particles, the phase difference between the electric field and the charged particle will produce a current. Based on the position of the electrode, there are three modes of lighting up: internal-electrode excitation, external-electrode excitation, and non-electrode excitation, as shown in Fig.2.

The internal-electrode excitation is to enclose the electrodes inside the cell. In the external-electrode mode, the electrodes 
are attached to the outside of the cell. In the non-electrode excitation mode, the electrodes are wound around cell as coils. The optically pumped magnetometer uses the external-electrode excitation.

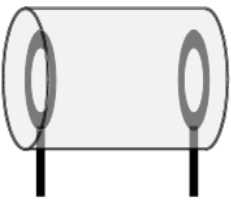

internal-electrode excitation

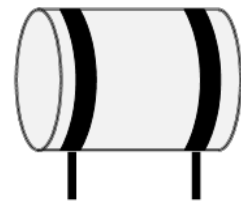

external-electrode excitation

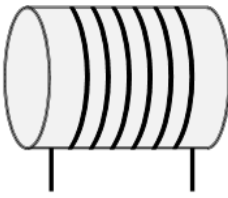

non-electrode excitation
Fig. 2. Three excitation modes of cell.

In order to know the impedance of the cell in stable working condition, it is important to obtain the equivalent electric parameter model of the cell. And, the cell can be considered as a gas discharge lamp. Since the middle of the 20th century, many scholars have been working on the modeling of gas discharge lamps. In the late 1940s, Francis proposed using a differential equation to approximate the electrical parameters of a gas discharge lamp based on three hypotheses[28-32]. The three hypotheses are:

1) The increase of free electron concentration $\mathrm{N}$ in discharge area is proportional to the instantaneous power of the lamp.

2) The decrease of electron concentration is proportional to the electron concentration $\mathrm{N}$ in the discharge area

3) The equivalent resistance of the lamp is inversely proportional to the free electron concentration $\mathrm{N}$.

The differential equation is as follows:

$$
\begin{gathered}
\mathrm{dN} / \mathrm{dt}=\mathrm{A} \cdot \mathrm{i} \cdot \mathrm{v}-\mathrm{B} \cdot \mathrm{N} \\
\mathrm{R}=\mathrm{v} / \mathrm{i}=\mathrm{F} / \mathrm{N}
\end{gathered}
$$

The parameters in the equations have lamp voltage $\mathrm{v}$, lamp current $\mathrm{i}$, average electron concentration $\mathrm{N}$ and lamp resistance R. Where A, B and F are constants. Combining (3) and (4) gives:

$$
\frac{\mathrm{d}\left(\frac{1}{\mathrm{R}}\right)}{\mathrm{dt}}=\frac{\mathrm{A} \cdot \mathrm{v}^{2}}{\mathrm{~F}} \cdot\left(\frac{1}{\mathrm{R}}\right)-\mathrm{B} \cdot\left(\frac{1}{\mathrm{R}}\right)=\frac{\mathrm{A} \cdot \mathrm{i}^{2}}{\mathrm{~F}} \cdot \mathrm{R}-\mathrm{B} \cdot\left(\frac{1}{\mathrm{R}}\right)
$$

The output voltage $\mathrm{V}(\mathrm{t})$ is a sinusoidal signal that $\mathrm{t}$ varies with time. The relationship between the equivalent resistance $\mathrm{R}(\mathrm{t})$ of cell and $\mathrm{V}(\mathrm{t})$ can be obtained by (5). Parameters in the model are $\mathrm{A} / \mathrm{F}=0.5, \mathrm{~B}=3190$, and the input current signal frequency is $50 \mathrm{MHz}$. By solving these differential equations, we calculated the equivalent resistance waveform as shown in Fig.3. It is a zoomed in the figure of the waveform after cell reaches a stable state. From Fig.3, it can be seen that when the signal frequency is $50 \mathrm{MHz}$, the equivalent resistance value of a cell in the stable state fluctuates with time in a tiny range, and the approximation can be regarded as a constant. Therefore, we can conclude that the cell of optically pumped magnetometer can exhibit the resistance characteristic in high-frequency excitation circuit.

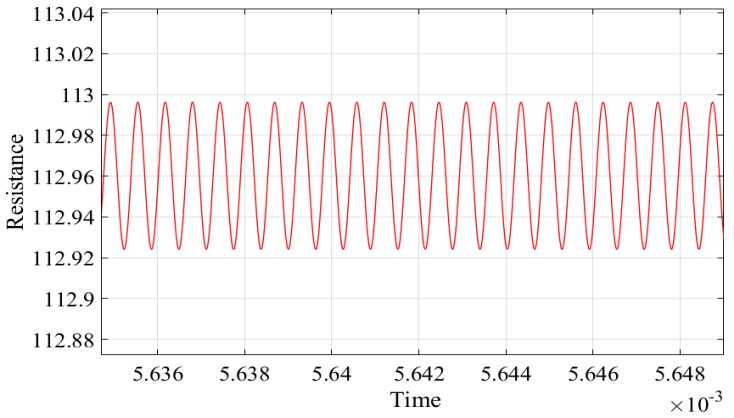

Fig. 3. The equivalent resistance simulation waveform of cell at $50 \mathrm{MHz}$.

\section{CALCULATION AND ANALYSIS OF IMPEDANCE MATCHING AND PASSBAND SELECTION}

\section{A. Calculation and analysis of transmitter matching network}

According to section II, the impedance of the MOSFET output is $\mathrm{R}_{\mathrm{Ls}}=10 \Omega$ and the impedance of coaxial transmission line is $R_{L 1}=50 \Omega$. So, it is necessary to design a transmitter matching network with source impedance $\mathrm{R}_{\mathrm{Ls}}=10 \Omega$ and load impedance of $\mathrm{R}_{\mathrm{L} 1}=50 \Omega$.

\section{1) Calculation and analysis of L-network}

The most commonly used structure is an L-network. This is a two-component network. Because the value of source impedance $\mathrm{R}_{\mathrm{Ls}}$ is less than the load impedance $\mathrm{R}_{\mathrm{L} 1}$, the network structure shown in Fig.4(a) is adopted, and the $\mathrm{X}_{\mathrm{L} 1}$ and $\mathrm{X}_{\mathrm{L} 2}$ in the circuit are the opposite of the reactance, and its vector equivalent model is shown in Fig.4 (b).

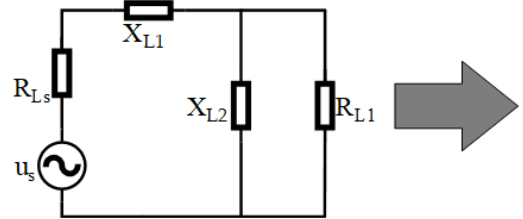

(a)

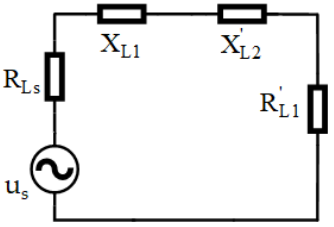

(b)
Fig. 4. (a)The basic form of L-network; (b) the equivalent circuit of L-network.

Les us define $\mathrm{Q}_{\mathrm{L} 1}=\mathrm{X}_{\mathrm{L} 1} / \mathrm{R}_{\mathrm{Ls}}$ and $\mathrm{Q}_{\mathrm{L} 2}=\mathrm{R}_{\mathrm{L} 1} / \mathrm{X}_{\mathrm{L} 2}$, therefore

$$
\begin{gathered}
\mathrm{R}_{\mathrm{L} 1}^{\prime}=\frac{\mathrm{R}_{\mathrm{L} 1}}{1+\mathrm{Q}_{\mathrm{L} 2}^{2}} \\
\mathrm{X}_{\mathrm{L} 2}^{\prime}=\frac{\mathrm{X}_{\mathrm{L} 2}}{1+1 / \mathrm{Q}_{\mathrm{L} 2}^{2}}
\end{gathered}
$$

The nodal quality factor of L-network is $\mathrm{Q}_{\mathrm{L}}$, and the conditions of the L-network impedance match are: $\mathrm{X}_{\mathrm{L} 1}=\mathrm{X}_{\mathrm{L} 2}$, $\mathrm{R}_{\mathrm{Ls}}=\mathrm{R}_{\mathrm{L} 1}^{\prime}$, and $\mathrm{Q}_{\mathrm{L}}=\mathrm{Q}_{\mathrm{L} 1}=\mathrm{Q}_{\mathrm{L} 2}$. According to these conditions and the above equations, it can be calculated

$$
\mathrm{Q}_{\mathrm{L}}=\sqrt{\frac{\mathrm{R}_{\mathrm{L} 1}}{\mathrm{R}_{\mathrm{Ls}}}-1}
$$




$$
\begin{aligned}
& X_{L 2}=R_{L 1} \cdot \sqrt{\frac{R_{L s}}{R_{L 1}-R_{L s}}} \\
& X_{L 1}=\sqrt{R_{L s} \cdot\left(R_{L 1}-R_{L s}\right)}
\end{aligned}
$$

The frequency of the high-frequency excitation signal is $\mathrm{f}_{0}$, the load factor of L-network is $\mathrm{Q}_{\mathrm{LL}}$, and $3 \mathrm{~dB}$ bandwidth is $\mathrm{BW}_{\mathrm{L} 0.7}$, so

$$
\begin{gathered}
\mathrm{Q}_{\mathrm{LL}}=\frac{1}{2} \mathrm{Q}_{\mathrm{L}} \\
\mathrm{BW}_{\mathrm{L} 0.7} \approx \frac{\mathrm{f}_{0}}{2 \mathrm{Q}_{\mathrm{LL}}}
\end{gathered}
$$

When source impedance $\mathrm{R}_{\mathrm{Ls}}=10 \Omega$, target impedance $\mathrm{R}_{\mathrm{L} 1}=50 \Omega$, working frequency $\mathrm{f}_{0}=50 \mathrm{MHz}$, we can calculate the loaded quality factor of L-network $\mathrm{Q}_{\mathrm{LL}}=1,3 \mathrm{~dB}$ bandwidth $\mathrm{BW}_{\mathrm{L} 0.7} \approx 25 \mathrm{MHz}$ with (6) to (12).

The load factor and $3 \mathrm{~dB}$ bandwidth of L-network are determined when we have the target impedance and source impedance. In the working frequency, although we can get higher energy transfer efficiency through parameter optimization, BWL $0.7 \approx 25 \mathrm{MHz}$ can't ensure the undesired harmonic components and interference to be suppressed. In order to be able to have loaded quality factor for tuning, and to adjust the $3 \mathrm{~dB}$ bandwidth, a third component can be introduced into L-network to form a T-network or a П-network.

2) Calculation and analysis of T-network

The basic circuit form of T-network as shown in Fig.5 (a). $\mathrm{X}_{\mathrm{T} 3}$ is divided into two parallel reactance components $\mathrm{X}_{\mathrm{T} 3 \mathrm{a}}$ and $\mathrm{X}_{\mathrm{T} 3 \mathrm{~b}}$. T-network can be equivalent to a double L-network model after inserting a hypothetical resistance $\mathrm{R}_{\text {Tin }}$, as shown in Fig.5 (b).

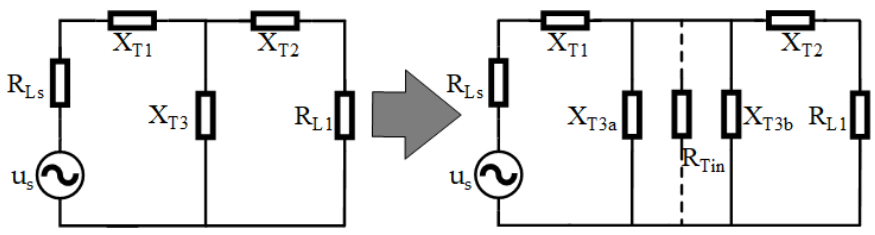

(a) (b)

$$
\mathrm{Q}_{\mathrm{T} 2}=\sqrt{\frac{\mathrm{R}_{\mathrm{Tin}}}{\mathrm{R}_{\mathrm{L} 1}}-1}
$$

The passband width of T-network is determined by $\mathrm{Q}_{\mathrm{T} 1}$ and $\mathrm{Q}_{\mathrm{T} 2}$. Because the value of $\mathrm{R}_{\mathrm{Ls}}$ is less than $\mathrm{R}_{\mathrm{L} 1}$, we can select $\mathrm{Q}_{\mathrm{T} 1}$ to calculate the parameters from the source impedance. The loaded quality factor of circuit is $\mathrm{Q}_{\mathrm{TL}}=\mathrm{Q}_{\mathrm{T} 1} / 2$, the $3 \mathrm{~dB}$

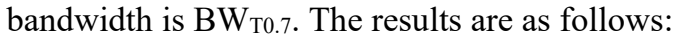

$$
\begin{gathered}
\mathrm{BW}_{\mathrm{T} 0.7} \approx \frac{\mathrm{f}_{0}}{2 \mathrm{Q}_{\mathrm{TL}}} \\
\mathrm{R}_{\mathrm{Tin}}=\left(1+\mathrm{Q}_{\mathrm{T} 1}^{2}\right) \mathrm{R}_{\mathrm{Ls}} \\
\mathrm{X}_{\mathrm{T} 1}=\mathrm{Q}_{\mathrm{T} 1} \cdot \mathrm{R}_{\mathrm{Ls}} \\
\mathrm{X}_{\mathrm{T} 2}=\mathrm{Q}_{\mathrm{T} 2} \cdot \mathrm{R}_{\mathrm{L} 1} \\
\mathrm{X}_{\mathrm{T} 3}=\mathrm{X}_{\mathrm{T} 3 \mathrm{a}}\left\|\mathrm{X}_{\mathrm{T} 3 \mathrm{~b}}=\left(\mathrm{R}_{\mathrm{Tin}} / \mathrm{Q}_{\mathrm{T} 1}\right)\right\|\left(\mathrm{R}_{\mathrm{Tin}} / \mathrm{Q}_{\mathrm{T} 2}\right)
\end{gathered}
$$

3) Calculation and analysis of $\Pi$-network

Fig.6 (a) shows the basic circuit of a П-network. Divide the $\mathrm{X}_{\pi 1}$ in the circuit into two series reactance components $\mathrm{X}_{\pi 1 \mathrm{a}}$ and $\mathrm{X}_{\pi 1 \mathrm{~b}}$. Insert a hypothetical resistance $\mathrm{R}_{\mathrm{Tin}}, \Pi$-network can be also equivalent to a double L-network model, as shown in Fig.6 (b)

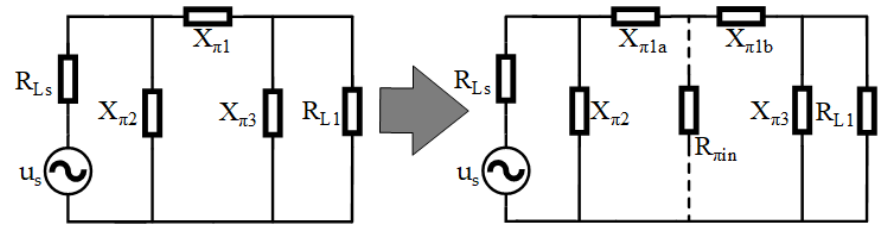

(a)

(b)

Fig. 6. (a)The basic form of П-network; (b) the double L-network equivalent circuit of it.

Similarly, according to the L-network analysis method, conditions for a $\Pi$-network impedance match are: $\mathrm{R}_{\pi \text { in }}<\mathrm{R}_{\mathrm{Ls}}$ and $\mathrm{R}_{\pi \text { in }}<\mathrm{R}_{\mathrm{L} 1}$. In Fig.6 (b), the nodal quality factor of the L-network composed of $\mathrm{X}_{\pi 2}$ and $\mathrm{X}_{\pi 1 \mathrm{a}}$ is defined as $\mathrm{Q}_{\pi 1}$, the nodal quality factor of the L-network composed of $\mathrm{X}_{\pi}$ and $\mathrm{X}_{\pi \mathrm{lb}}$ is defined as $\mathrm{Q}_{\pi 2}$, then

$$
\begin{aligned}
& \mathrm{Q}_{\pi 1}=\sqrt{\frac{\mathrm{R}_{\mathrm{Ls}}}{\mathrm{R}_{\pi \mathrm{in}}}-1} \\
& \mathrm{Q}_{\pi 2}=\sqrt{\frac{\mathrm{R}_{\mathrm{L} 1}}{\mathrm{R}_{\pi \mathrm{in}}}-1}
\end{aligned}
$$

The passband width of $\Pi$-network is determined by $\mathrm{Q}_{\pi 1}$ and $\mathrm{Q}_{\pi 2}$. Because the value of $\mathrm{R}_{\mathrm{Ls}}$ is less than $\mathrm{R}_{\mathrm{L} 1}$, we can select $\mathrm{Q}_{\pi 2}$ to calculate the parameters of the load impedance. The loaded quality factor of circuit is $\mathrm{Q}_{\pi \mathrm{L}}=\mathrm{Q}_{\pi 2} / 2$, the $3 \mathrm{~dB}$ bandwidth is $\mathrm{BW}_{\pi 0.7}$. This gives us:

$$
\mathrm{BW}_{\pi 0.7} \approx \frac{\mathrm{f}_{0}}{2 \mathrm{Q}_{\pi \mathrm{L}}}
$$




$$
\begin{gathered}
\mathrm{R}_{\pi \text { in }}=\mathrm{R}_{\mathrm{L} 1} /\left(1+\mathrm{Q}_{\pi 2}^{2}\right) \\
\mathrm{X}_{\pi 3}=\mathrm{R}_{\mathrm{L} 1} / \mathrm{Q}_{\pi 2} \\
\mathrm{X}_{\pi 2}=\mathrm{R}_{\mathrm{LS}} / \mathrm{Q}_{\pi 1} \\
\mathrm{X}_{\pi 1}=\mathrm{X}_{\pi \mathrm{la}}+\mathrm{X}_{\pi 1 \mathrm{~b}}=\mathrm{R}_{\pi \text { in }}\left(\mathrm{Q}_{\pi 1}+\mathrm{Q}_{\pi 2}\right)
\end{gathered}
$$

B. Calculation and analysis of receiver matching network

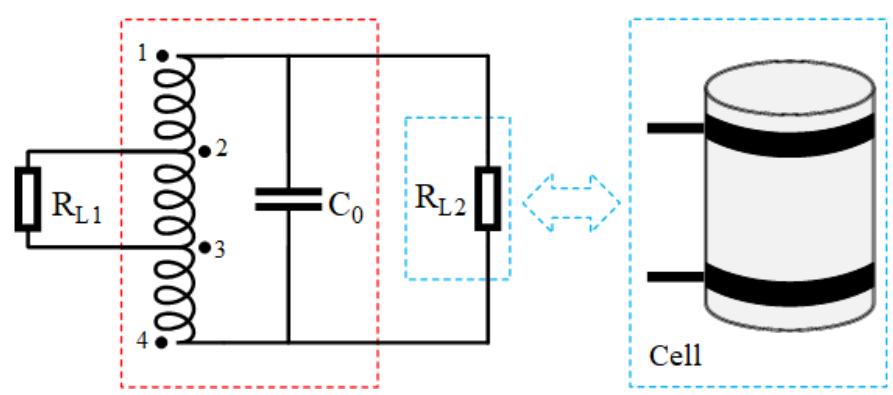

Fig. 7. Design of impedance transformation and LC parallel resonant network in the receiver circuit.

As described in section II, the equivalent model of the cell shows that cell is a resistance component. Because an accurate resistance value is difficult to obtain, and it is larger than $50 \Omega$, the input impedance needs to be raised with a self-coupled coil. An LC parallel resonant network composed of the self-coupled coil and the capacitance is designed to do $50 \mathrm{MHz}$ frequency selection. The design of receiver circuit is shown in Fig.7.

In the ideal case, we take the self-coupled coil as object, assumes that the primary side (the part between tap 2 and tap 3 in Fig.7) and secondary side (the part between tap 1 and tap 4 in Fig.7) turn ratio of $1: n$, then the primary side input resistance and secondary side output resistance turn ratio of $1: \mathrm{n}^{2}$. With the LC parallel resonant network shown in the red dotted line in Fig.7 as object, assumes that the secondary side inductance value is $\mathrm{L}_{14}$, the capacitance value is $\mathrm{C}_{0}$, and the loaded quality factor of the circuit is $\mathrm{Q}_{\mathrm{L} 0}$, The LC parallel resonant network center frequency is $\mathrm{f}_{0}$, then

$$
\begin{aligned}
& \mathrm{Q}_{\mathrm{L} 0}=\mathrm{R}_{0} / 2 \pi \mathrm{f}_{0} \mathrm{~L}_{14} \\
& \mathrm{R}_{0}=\left(\mathrm{n}^{2} \mathrm{R}_{\mathrm{L} 1}\right) \| \mathrm{R}_{\mathrm{L} 2} \\
& \mathrm{f}_{0}=\frac{1}{2 \pi \sqrt{\mathrm{L}_{14} \mathrm{C}_{0}}}
\end{aligned}
$$

\section{SimULATION EXPERIMENT OF TRANSMITTER AND RECEIVER CIRCUIT}

Advanced Design System (ADS) software of Agilent was used to simulate circuit matching effects. $\mathrm{S}_{\mathrm{ij}}$-the $\mathrm{S}$ parameter can evaluate the matching network performance. For a dual-port network, $S_{i j}$ represents energy measured at i port after injecting energy into j port. Port 1 serves as the input port and Port 2 serves as the output port, $S_{11}$ represents the reflection loss, that is, how much energy is reflected back to the input port, the smaller the better. A general recommendation is $\mathrm{dB}\left(\mathrm{S}_{11}\right)$ $<-20 . S_{21}$ indicates the insertion loss, which is how much energy is transferred to the output port, the larger the better. The ideal value is $0 \mathrm{~dB}$, and the greater the $\mathrm{S}_{21}$, the higher the efficiency of transmission. A general recommendation is $\mathrm{dB}\left(\mathrm{S}_{21}\right)>-3$.

\section{A. Simulation experiment of transmitter circuit}

Compared with L-network, T-network and П-network can easily design circuit parameters. Because of the high-frequency signal working conditions, the error of the capacitance in the actual device selection is better controlled than the inductance. Circuit design minimizes the use of inductance, so the two T-network structures are shown in Fig.8(a) and Fig.8(c), and the two T-network structures shown in Fig.9(a) and Fig.9(c) can be designed.

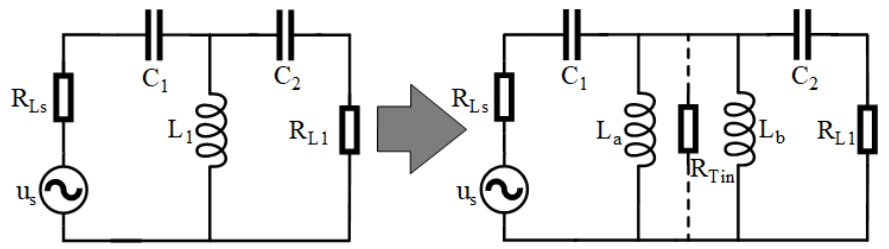

(a)

(b)

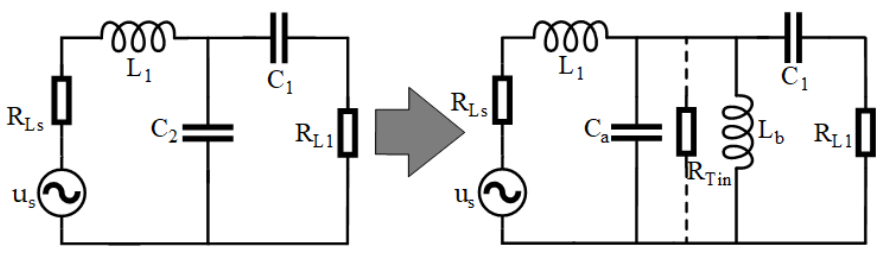

(c)

(d)

Fig. 8. (a)One of the T-network design of transmitter circuit;

(b) The double L-network equivalent model of (a);

(c) Another T-network design of transmitter circuit;

(d) The double L-network equivalent model of (c).

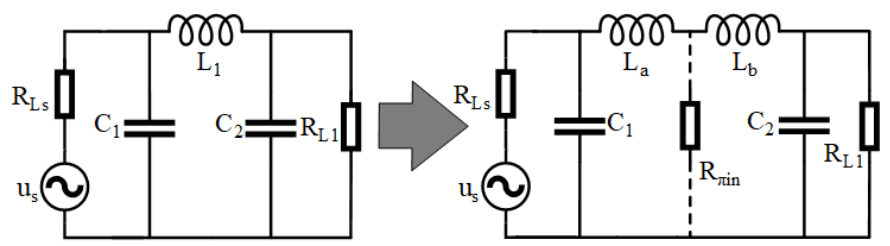

(a)

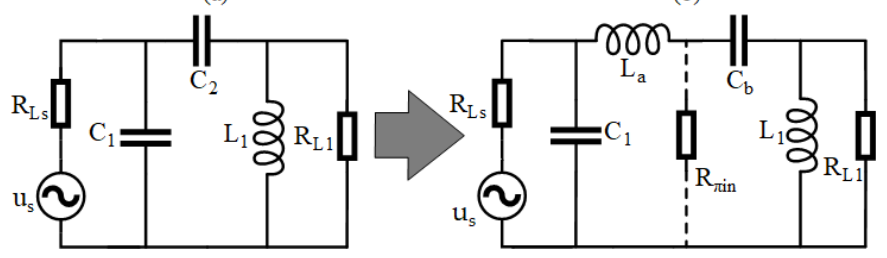

(c)

(d)

Fig. 9. (a)One of the П-network design of transmitter circuit;

(b) The double L-network equivalent model of (a);

(c) Another П-network design of transmitter circuit;

(d) The double L-network equivalent model of (c). 
1) Simulation experiment of T-network

In general, we make a narrow band-pass or band-stop filter such that its $3 \mathrm{~dB}$ bandwidth is less than $10 \%$ of its center frequency value. So, we set the $3 \mathrm{~dB}$ bandwidth of $50 \mathrm{MHz}$ high-frequency excitation circuit to $2.5 \mathrm{MHz}$.

Take ВWт0.7 $=2.5 \mathrm{MHz}$ into (13) to (19). If the circuit structure of Fig.8(a) is adopted, in the ideal case, $\mathrm{C}_{1}=15.9 \mathrm{pF}$, $\mathrm{C}_{2}=7.15 \mathrm{pF}$, and $\mathrm{L}_{1}=442 \mathrm{nH}$. The simulation results are shown in Fig.10(a). At 50MHz, $\mathrm{dB}\left(\mathrm{S}_{11}\right)=-66.008 \mathrm{~dB}$ ( $\mathrm{m} 1$ in Fig. 10(a)), $\mathrm{dB}\left(\mathrm{S}_{21}\right)=0 \mathrm{~dB} \quad(\mathrm{~m} 2 \quad$ in $\quad$ Fig.10(a)), $3 \mathrm{~dB} \quad$ bandwidth

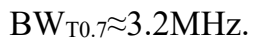

If the circuit structure of Fig.8(c) is adopted, in the ideal case, $\mathrm{L}_{1}=636.62 \mathrm{nH}, \mathrm{C}_{1}=7.15 \mathrm{pF}, \mathrm{C}_{\mathrm{a}}=15.9 \mathrm{pF}$, and $\mathrm{L}_{b}=1434 \mathrm{nH}$. Because $2 \pi \mathrm{f}_{0} \mathrm{C}_{\mathrm{a}}>1 /\left(2 \pi \mathrm{f}_{0} \mathrm{Lb}\right)$, the parallel circuit of $\mathrm{C}_{\mathrm{a}}$ and $\mathrm{Lb}_{\mathrm{b}}$ is capacitive. Optimized by ADS, $\mathrm{C}_{2}=8.815 \mathrm{pF}$. The simulation results are shown in Fig.10(b). At 50MHz, dB( $\left.\mathrm{S}_{11}\right)=-66.232 \mathrm{~dB}$ ( $\mathrm{m} 1$ in Fig.10(b)), dB( $\left.\mathrm{S}_{21}\right)=0 \mathrm{~dB}$ (m2 in Fig.10(b)), 3dB bandwidth $\mathrm{BW}_{\text {т0. }} \approx 4.4 \mathrm{MHz}$.

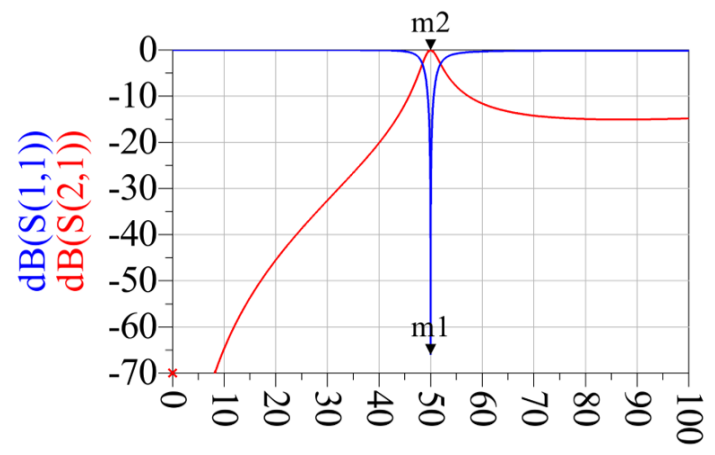

freq, $\mathrm{MHz}$

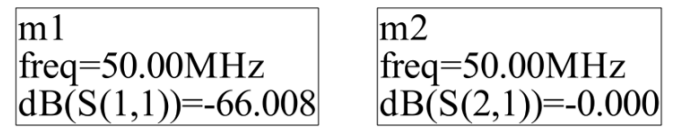

(a)

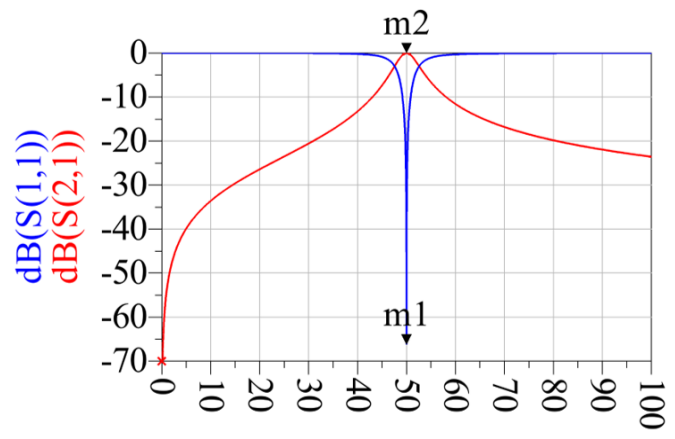

freq, $\mathrm{MHz}$

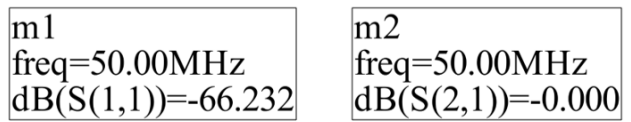

(b)

Fig. 10. (a)The simulation results of T-network in Figure9(a);

(b) The simulation results of T-network in Figure9 (c).
2) Simulation experiment of П-network

As described before, we also set the $3 \mathrm{~dB}$ bandwidth of $50 \mathrm{MHz}$ high-frequency excitation circuit to $2.5 \mathrm{MHz}$.

Take $\mathrm{BW}_{\pi 0.7}=2.5 \mathrm{MHz}$ into (20) to (26). If the circuit structure of Fig. 9 (a) is adopted, in the ideal case, $\mathrm{C}_{1}=2.83 \mathrm{pF}$, $\mathrm{C}_{2}=1.27 \mathrm{pF}$, and $\mathrm{L}_{1}=11.495 \mathrm{nH}$. The simulation results are shown in Fig.11(a). At 50MHz, dB( $\left.\mathrm{S}_{11}\right)=-56.060 \mathrm{~dB}(\mathrm{~m} 1$ in Fig.11(a)), $d B\left(S_{21}\right)=0 d B(m 2$ in Fig.11(a)), 3dB bandwidth $\mathrm{BW}_{\pi 0.7} \approx 3.6 \mathrm{MHz}$.

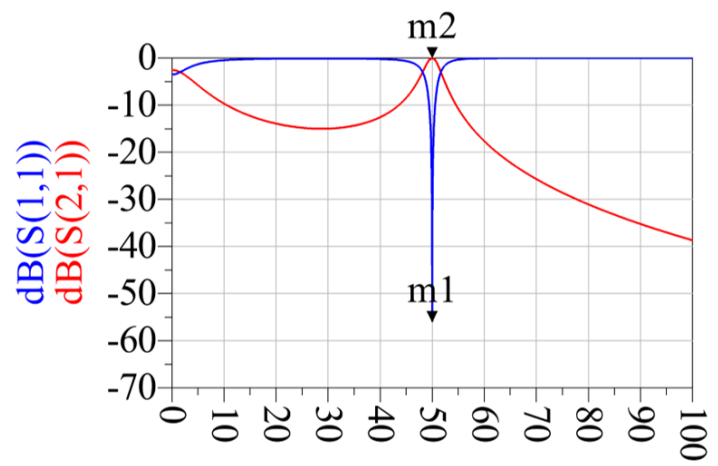

freq, $\mathrm{MHz}$

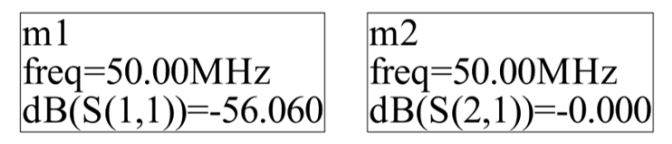

(a)

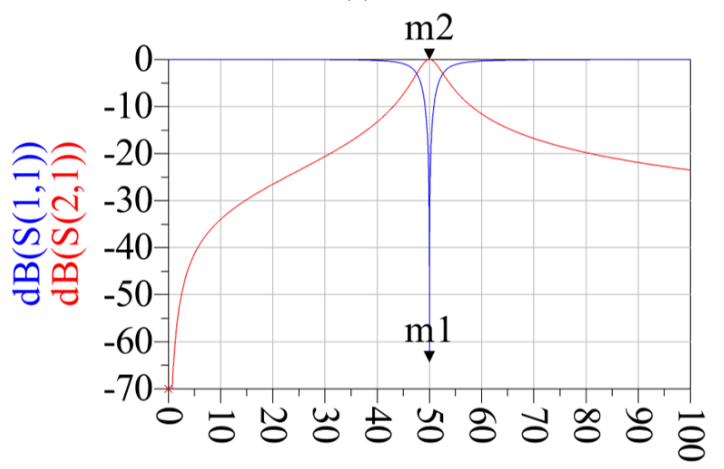

freq, $\mathrm{MHz}$

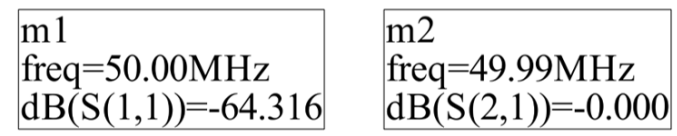

(b)

Fig. 11. (a)The simulation results of П-network in Figure10(a); (b) The simulation results of П-network in Figure10(c).

If the circuit structure of Fig.9(c) is adopted, in the ideal case, $\mathrm{C}_{1}=2.83 \mathrm{pF}, \mathrm{L}_{1}=7.96 \mathrm{nH}, \mathrm{L}_{\mathrm{a}}=3.58 \mathrm{nH}$ and $\mathrm{C}_{b}=1.27 \mathrm{nF}$. Because $1 /\left(2 \pi f_{0} C_{b}\right)>2 \pi f_{0} L_{a}$, the parallel circuit of $C_{b}$ and $L_{a}$ is capacitive. Optimized by $\mathrm{ADS}, \mathrm{C}_{2}=2.3 \mathrm{nF}$. The simulation results are shown in Fig.11(b). At $50 \mathrm{MHz}, \mathrm{dB}\left(\mathrm{S}_{11}\right)=-64.316 \mathrm{~dB}(\mathrm{~m} 1$ in Fig.11(b)), $d B\left(\mathrm{~S}_{21}\right)=0 \mathrm{~dB}$ ( $\mathrm{m} 2$ in Fig.11(b)), 3dB bandwidth $\mathrm{BW}_{\pi 0.7} \approx 4.8 \mathrm{MHz}$. 


\section{B. Simulation experiment of receiver circuit}

Because of the higher value of load factor QL0, the narrower the $3 \mathrm{~dB}$ bandwidth, and the better the frequency selectivity, so, with (27) and (28), it is necessary to make the turn ratio in as large as possible, and $\mathrm{L}_{14}$ (the value of inductance between tap 1 and tap 4 in Fig.7) as small as possible. At the same time, the value of $n$ is obtained after $R_{L 1}$ and $R_{L 2}$ are determined. according to (29), at the center frequency $\mathrm{f}_{0}$, it should be to increase $\mathrm{C}_{0}$ and reduce $\mathrm{L}_{14}$ as much as possible to maximize the impedance matching effect and frequency selectivity.

Design a comparison experiment, $\mathrm{f}_{0}=50 \mathrm{MHz}$, in the ideal case, the three groups of $\mathrm{C}_{0}$ and $\mathrm{L}_{14}$ values are calculated, as in Table I.

TABLE I. The calculated values of $\mathrm{C}_{0}$ and $\mathrm{L}_{14}$ in comparison experiment.

\begin{tabular}{cccc}
\hline \hline & Experiment 1 & Experiment 2 & Experiment 3 \\
\hline $\begin{array}{c}\text { Values of } \\
\mathrm{C}_{0}(\mathrm{pF})\end{array}$ & 51.0 & 100.3 & 150.1 \\
$\begin{array}{c}\text { Values of } \\
\mathrm{L}_{14}(\mathrm{nH})\end{array}$ & 205.2 & 102.0 & 67.8 \\
\hline \hline
\end{tabular}

We assume that the impedance of cell is $450 \Omega$ when lighting stably, due to the transmission line impedance of $50 \Omega$, the primary side and secondary side turn ratio of the self-coupled coil is 1:3. Inductance is wound handcrafted, the number of turns is proportional to the inductance value when the coil diameter and line diameter are the same.
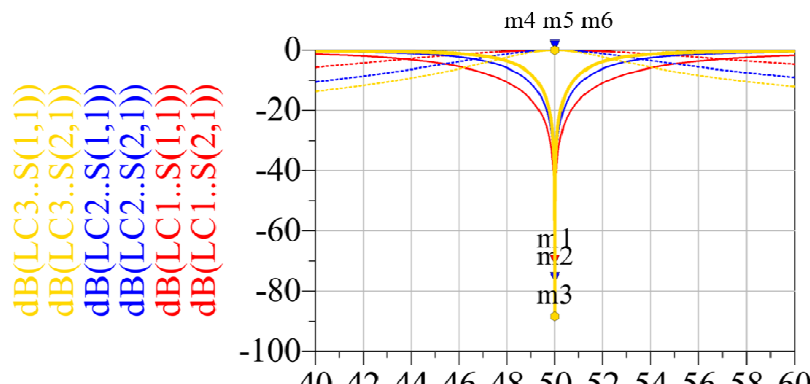

4042444648505254565860

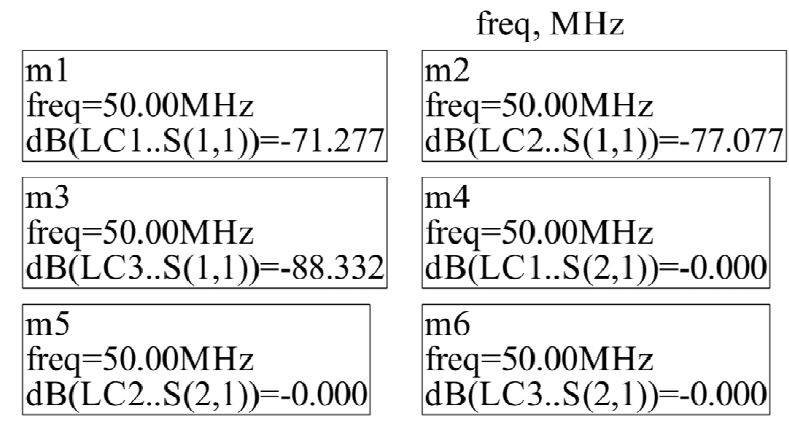

Fig. 12. The simulation results of the receiver matching network comparison experiment with $\mathrm{C}_{0}$ and $\mathrm{L}_{14}$ in table $\mathrm{I}$.
The simulation results are shown in Fig.12. The red curve in the graph is the result of experiment 1 from table I. The blue curve is the result of experiment 2, and the yellow curve is the result of experiment 3. Solid line is $S_{11}$, and dotted line is $S_{21}$. At $50 \mathrm{MHz}$, value of the best match load $\mathrm{R}_{\mathrm{L} 2}$ in experiment 1 is $487 \Omega, \mathrm{dB}\left(\mathrm{S}_{11}\right)=-71.277 \mathrm{~dB}(\mathrm{~m} 1$ in Fig. 12$), \mathrm{dB}\left(\mathrm{S}_{21}\right)=0 \mathrm{~dB}(\mathrm{~m} 4$ in Fig. 12), $3 \mathrm{~dB}$ bandwidth $\mathrm{BW}_{0.7} \approx 13 \mathrm{MHz}$. Value of the best match load $\mathrm{R}_{\mathrm{L} 2}$ in experiment 2 is $459 \Omega, \mathrm{dB}\left(\mathrm{S}_{11}\right)=-77.077 \mathrm{~dB}$ (m2 in Fig.12), dB( $\left.\mathrm{S}_{21}\right)=0 \mathrm{~dB}$ (m5 in Fig.12), $3 \mathrm{~dB}$ bandwidth $\mathrm{BW}_{0.7} \approx 7 \mathrm{MHz}$. Value of the best match load $\mathrm{R}_{\mathrm{L} 2}$ in experiment 3 is $454 \Omega, \mathrm{dB}\left(\mathrm{S}_{11}\right)=-88.332 \mathrm{~dB}(\mathrm{~m} 3$ in Fig. 12$), \mathrm{dB}\left(\mathrm{S}_{21}\right)=0 \mathrm{~dB}(\mathrm{~m} 6$ in Fig. 12), $3 \mathrm{~dB}$ bandwidth $\mathrm{BW}_{0.7} \approx 5 \mathrm{MHz}$.

The experiment shows that the primary side and secondary side turn ratio of self-coupled coil 1: $n$ give $n$ times impedance uplifting. At the same time, by reducing the inductance value and increasing the capacitance value in LC parallel resonant network, we can increase the load quality factor and reduce the $3 \mathrm{~dB}$ bandwidth of the circuit.

\section{CONCLUSIONS}

In this paper, the cell of optically pumped magnetometer is equivalent to a stable resistivity element after being light up by high-frequency signal excitation. In the ideal condition, the transmitter matching network of high-frequency excitation circuit can be designed as a T-network or a П-network. When the source impedance $\mathrm{R}_{\mathrm{Ls}}=10 \Omega$, and the transmission line impedance $\mathrm{R}_{\mathrm{L} 1}=50 \Omega$, both insertion loss $\mathrm{S}_{21}$ of two networks can achieve optimal values, namely, 0dB. T-network in Fig.8(a) has the best performance at frequency selectivity with a $3 \mathrm{~dB}$ bandwidth $\mathrm{BW}_{\mathrm{T} 0.7}$ of around 3.2MHz, and T-network in Fig.8(c) has the best performance at energy transfer with a reflection loss $\mathrm{S}_{11}$ of around $-66.232 \mathrm{~dB}$. In the ideal state, the receiver matching network of high-frequency excitation circuit can realize impedance matching and frequency selection simultaneously with the combination of a self-coupled coil and an LC parallel resonant network. And the power consumption of the whole high-frequency excitation circuit of cell in the optically pumped magnetometer is only about $6 \mathrm{~W}$.

The circuit analysis method and the simulation results presented in this paper can effectively guide us to produce a high-frequency excitation circuit for optically pumped magnetometer with high energy transmission efficiency.

\section{ACKNOWLEDGMENT}

This work was supported by the Special Projects for Monitoring, Warning and Prevention of Major Natural Disasters, the National Key Research and Development Program of China 2018 (Grant No. 2018YFC1503803 and 2018YFC1503903). The authors would like to thank the Key Laboratory of Geophysical Exploration Equipment (Jilin University ) , Ministry of Education for their additional assistance. 


\section{REFERENCES}

[1] Dong H and Chang Z 2010 A Further Review of the Quantum Magnetometers Chinese J. Eng. Geophys. 7 460-70

[2] Chen X, Zhang H and Zou S 2016 Measurement Sensitivity Improvement of All-Optical Atomic Spin Magnetometer by Suppressing Noises Sensors 16896

[3] Plante M K, MacFarlane D L, McGregor D D, Slocum R E, Sampson W M and Brown A W 2010 Generalized theory of double-resonance optically pumpeding of ^ $\{4\}$ He Phys. Rev. A 8213837

[4] Pradhan S, Mishra S, Behera R, Poornima and Dasgupta K 2015 An atomic magnetometer with autonomous frequency stabilization and large dynamic range Rev. Sci. Instrum. 8663104

[5] Olsen N, Hulot G and Sabaka T J 2010 Measuring the Earth's Magnetic Field from Space: Concepts of Past, Present and Future Missions Space Sci. Rev. 155 65-93

[6] Schultze V, Schillig B, Ijsselsteijn R, Scholtes T, Woetzel S and Stolz R 2017 An optically pumped magnetometer working in the light-shift dispersed Mz mode Sensors (Switzerland) 17

[7] Matzka J, Chulliat A, Mandea M, Finlay C C and Qamili E 2010 Geomagnetic Observations for Main Field Studies: From Ground to Space Space Sci. Rev. 155 29-64

[8] Leger J-M, Bertrand F, Jager T, Le Prado M, Fratter I and Lalaurie J-C 2009 Swarm Absolute Scalar and Vector Magnetometer Based on Helium 4 Optically pumpeding Procedia Chem. 1 634-7

[9] Hulot G, Vigneron P, Léger J M, Fratter I, Olsen N, Jager T, Bertrand F, Brocco L, Sirol O, Lalanne X, Boness A and Cattin V 2015 Swarm's absolute magnetometer experimental vector mode, an innovative capability for space magnetometry Geophys. Res. Lett. 42 1352-9

[10] Jager T, Le J-M, Bertrand F, Fratter I and Lalaurie J-C 2010 SWARM Absolute Scalar Magnetometer accuracy: Analyses and measurement results 2010 IEEE Sensors (IEEE) pp 2392-5

[11] Fratter I, Léger J-M, Bertrand F, Jager T, Hulot G, Brocco L and Vigneron P 2016 Swarm Absolute Scalar Magnetometers first in-orbit results Acta Astronaut. 121 76-87

[12] Weis A 2012 Optically pumped alkali magnetometers for biomedical applications Europhys. News 43 20-3

[13] Kim Y J, Savukov I, Huang J H and Nath P 2017 Magnetic microscopic imaging with an optically pumped magnetometer and flux guides Appl. Phys. Lett. 110

[14] Liao S-H, Huang H-S, Chieh J-J, Su Y-K, Tong Y-F and Huang K-W 2017 Characterizations of Anti-Alpha-Fetoprotein-Conjugated Magnetic Nanoparticles Associated with Alpha-Fetoprotein for Biomedical Applications Sensors 172018

[15] Seltzer S J, Meares P J and Romalis M V. 2006 Synchronous Optically pumpeding of Quantum Revival Beats for Atomic Magnetometery

[16] Huang K-K, Li N and Lu X-H 2012 A High Sensitivity Laser-Pumped Cesium Magnetometer Chinese Phys. Lett. 29100701

[17] McNeil B 2015 Due credit for Maxwell-Bloch equations Nat. Photonics 9 207-207

[18] Kobayashi M 2004 Towards a general solution of the inhomogeneous Bloch equation J. Math. Phys. 45 486-94

[19] Plakhotnik T 2006 Optical Bloch equations and enhanced decay of Rabi oscillations in strong driving fields Chem. Phys. 321 337-40

[20] Gu Y, Shi R Y and Wang Y H 2014 Study on sensitivity-related parameters of distributed feedback laser-pumped cesium atomic magnetometer Acta Phys. Sin. 63110701

[21] Li N, Huang K K and Lu X H 2013 Study on the sensitivity of laser-pumped cesium atomic magnetometer Acta Phys. Sin. 62 133201

[22] Gilles H, Hamel J and Chéron B 2001 Laser pumped 4He magnetometer Rev. Sci. Instrum. 72 2253-60

[23] Shinki Y, Shibata K, Mansour M and Kanaya H 2017 Impedance Matching Antenna-Integrated High-Efficiency Energy Harvesting Circuit Sensors 171763

[24] Lin S and Xu J 2017 Effect of the matching circuit on the electromechanical characteristics of sandwiched piezoelectric transducers Sensors (Switzerland) $\mathbf{1 7}$

[25] Silva F G S, De Lima R N, Freire R C S and Plett C 2013 A switchless multiband impedance matching technique based on multiresonant circuits IEEE Trans. Circuits Syst. II Express Briefs 60 $417-21$
Nallam N and Chatterjee S 2011 Design of concurrent multi-band matching networks Proc. - IEEE Int. Symp. Circuits Syst. 2 201-4 Hu Z, Huang C, He S and You F 2016 Tri-band matching technique based on characteristic impedance transformers for concurrent tri-band power amplifiers design IEEE Reg. 10 Annu. Int. Conf. Proceedings/TENCON 2016-Janua 1-3

Gan Z 2012 Equivalent-Ion Model of the Mixed Gas Discharge 2012 Asia-Pacific Power Energy Eng. Conf. 1-4

Anton J C, Blanco C, Ferrero F, Roldan P and Zissis G 2002 An equivalent conductance model for high intensity discharge lamps Conference Record of the 2002 IEEE Industry Applications Conference. 37th IAS Annual Meeting (Cat. No.02CH37344) vol 2(IEEE)pp 1494-8

] Sumini M, Mostacci D, Tartari A, Mazza A, Cucchi G, Isolan L, Buontempo F, Zironi I and Castellani G 2017 Dose-current discharge correlation analysis in a Mather type Plasma Focus device for medical applications Radiat. Phys. Chem. 140 452-7

Pipa A V., Koskulics J and Brandenburg R 2012 Approach of the simplest equivalent circuit for determination of charge transferred through the gas gap in pulsed dielectric barrier discharge Hakone XIII 115112 4-8

van de Sande M J and van der Mullen J J A M 2002 Thomson scattering on a low-pressure, inductively-coupled gas discharge lamp J. Phys. D. Appl. Phys. 35 1381-91 